\title{
Political Abuse of Psychiatry in the Soviet Union and in China: Complexities and Controversies
}

\author{
Richard J. Bonnie, LLB
}

J Am Acad Psychiatry Law 30:136-44, 2002

On first glance, political abuse of psychiatry appears to represent a straightforward and uncomplicated story: the deployment of medicine as an instrument of repression. Psychiatric incarceration of mentally healthy people is uniformly understood to be a particularly pernicious form of repression, because it uses the powerful modalities of medicine as tools of punishment, and it compounds a deep affront to human rights with deception and fraud. Doctors who allow themselves to be used in this way (certainly as collaborators, but even as victims of intimidation) betray the trust of society and breach their most basic ethical obligations as professionals.

When the story is so straightforward, political abuse of psychiatry is universally condemned. Even regimes that sponsor psychiatric repression find it morally embarrassing to admit that they engage in such a corrupt practice. When the Soviet Union was defending its suppression of political and religious dissent, it steadfastly denied allegations of psychiatric repression-allegations that have now been well documented $^{1,2}$ and are no longer contested by the psychiatric leadership in Russia and other post-Soviet states. ${ }^{3}$

If this were the whole story, political abuse of psychiatry would take its odious place alongside torture and other abuses of state power and perversions of medical ethics, but it would not be deeply interesting, either morally or sociologically. However, corruption is not the whole story, and political abuse of

Mr. Bonnie is John S. Battle Professor of Law and Director of the Institute of Law, Psychiatry and Public Policy at the University of Virginia, Charlottesville, VA. Address correspondence to: Richard J. Bonnie, University of Virginia School of Law, 580 Massie Road, Charlottesville, VA 22903. E-mail: rbonnie@virginia.edu psychiatry is more complicated than it first appears. Most important, whether the dissident individuals subjected to psychiatric confinement are (or are not) mentally ill is often contestable, especially when culturally embedded features of psychopathology are taken into account. The mental health of dissidents could be contested, even if diagnoses were grounded in a single internationally recognized system of classification, but the problem is all the more complicated when psychiatrists in different societies are trained to understand normality and psychopathology in different ways. Taking into account culturally linked ambiguities in psychiatric diagnosis, it seems likely that at least some cases of alleged abuse represent good-faith efforts by psychiatrists to apply prevailing psychiatric knowledge in politically repressive societies. Thus, two explanations compete for attention in cases of political abuse: corruption and culture.

There is a second complicating factor. In the "uncomplicated story," human rights and medical ethics are perfectly aligned. Intentional misdiagnosis and naked psychiatric punishment amount to simultaneous violations of human rights and breaches of medical ethics. But what is the normative significance of the fact that some people apprehended for dissident conduct are mentally ill? From a human rights perspective, criminal intervention in such cases is still a violation of human rights, because the state has no legitimate authority to arrest anyone for political or religious expression. Whether or not the person is mentally ill, the conduct itself is not properly subject to prohibition or punishment. Moreover, under contemporary principles of mental health law, codified in many countries, a person who 
has mental illness is not properly subject to coerced treatment solely for nondangerous political or religious expression, because such a person does not represent a sufficiently serious threat to himself or others to justify the use of coercion. However, it is by no means clear that a physician is behaving unethically if, against a person's wishes, she treats a person who has mental illness to ameliorate a serious condition that happens to be manifested by political or religious expression. Coerced treatment may be a justified exercise of paternalism in such cases, especially if the patient has no capacity to make a rational treatment decision.

These two issues - cross-cultural ambiguities of psychiatric diagnosis and divergent norms of human rights and medical ethics - explain why recent allegations of political abuse of psychiatry in China, allegations strongly supported by Robin Munro's extensive research, ${ }^{4}$ have stirred up so much controversy. In this brief essay, I reflect on the connection between the Soviet and Chinese experiences and the evolution of mental health law and ethics in the United States.

\section{Soviet Psychiatry}

Beginning in the early 1970s reports began to reach the West that political and religious dissidents were being incarcerated in maximum-security psychiatric hospitals in the Soviet Union without medical justification. In 1977, the World Psychiatric Association (WPA) condemned the Soviet Union for this practice, and six years later, the All-Union Society of Neuropathologists and Psychiatrists resigned from the WPA rather than face almost certain expulsion. Throughout this period, while reports of continued repression multiplied, Soviet psychiatric officials denied the charges of abuse and refused to permit international bodies to see the patients and hospitals in question. ${ }^{5,6}$ In 1989, however, the stonewalling of Soviet psychiatry was overtaken by glasnost and perestroika. Over the objection of the psychiatric leadership, the Soviet government allowed a delegation of psychiatrists from the United States, representing the U.S. Government, to conduct extensive interviews of suspected victims of abuse.

The 1989 investigation had two major components. Some members of the delegation conducted intensive clinical interviews with 27 patients whose names had been provided to the delegation by various human rights organizations, the U.S. Helsinki
Commission, and the State Department. Three clinical teams administered standardized psychiatric interview instruments incorporating internationally accepted diagnostic criteria and also interviewed each subject on the forensic and human rights aspects of the case. Separate interviews were also conducted with family members. Soviet psychiatrists were permitted to observe the interview if the subject consented. The entire interview protocol usually took one full day. Meanwhile, other delegation members made site visits to hospitals selected by the delegation and disclosed to the Soviets only a few days before the delegation's arrival.

The investigation by the U.S. delegation provided unequivocal proof that the tools of coercive psychiatry had been used, even in the late 1980s, to hospitalize persons who were not mentally ill and whose only transgression had been the expression of political or religious dissent. ${ }^{1}$ Most of the patients interviewed by the delegation had been charged with political crimes such as "anti-Soviet agitation and propaganda" or "defaming the Soviet state." Their offenses involved behavior such as writing and distributing anti-Soviet literature, political organizing, defending the rights of disabled groups, and furthering religious ideas.

Under applicable laws of Russia and the other former Soviet Republics, a person charged with a crime could be subjected to "custodial measures of a medical nature" if the criminal act was proved and the person was found "nonimputable" due to mental illness. ${ }^{7}$ Nonimputable offenders could be placed in maximum security hospitals (the notorious "special hospitals") or in ordinary hospitals, depending on their social dangerousness. All the persons interviewed by the delegation had been found nonimputable and socially dangerous and confined in special hospitals after criminal proceedings that deviated substantially from the general requirements specified in Soviet law. Typically, the patients reported that they had been arrested, taken to jail, taken to a hospital for forensic examination, and then taken to another hospital under a compulsory treatment order, without ever seeing an attorney or appearing in court. $^{8}$

The delegation found that there was no clinical basis for the judicial finding of nonimputability in 17 of these cases. In fact, the delegation found no evidence of mental disorder of any kind in 14 cases. It is likely that these individuals are representative of 
many hundreds of others who were found nonimputable for crimes of political or religious dissent in the Soviet Union, mainly between 1970 and 1990.

The delegation also found conditions in the special hospitals to be appallingly primitive and restrictive. Patients were denied basic rights, even to keep a diary or possess writing materials or books, and they were fearful of retaliation if they complained about their treatment, about abusive conduct by the staff, or about restrictive hospital rules or practices. No system existed for resolving patients' grievances.

Most disturbing, the delegation assembled compelling evidence that medication was used widely for punitive purposes. High doses of antipsychotic drugs were routinely administered by injection in a 10 - to 15 -day regimen to punish violators of hospital rules and to treat "delusions of reformism" and "antiSoviet thoughts." In addition, medical records and interviews of patients also showed that Soviet psychiatrists used a highly aversive drug called sulfazine for the ostensible purpose of enhancing treatment responses to neuroleptic medication. In the view of the U.S. psychiatrists, however, the severe pain, immobility, fever, and muscle necrosis produced by this medication, as well as the documented pattern of its use in 10 of the interviewed patients, strongly suggested that it had been used for punitive purposes. Other treatments, including insulin coma, strict physical restraints, and atropine injections, had been used in patients in whom the delegation found no evidence of psychosis or other significant symptoms.

Although the most punitive cases of Soviet psychiatric abuse involved criminal commitments to the notorious special hospitals, it is likely that many hundreds, if not thousands, of additional abuses were effected through the noncriminal procedure of urgent hospitalization, a process roughly equivalent to what is called civil commitment in this country. Although a criminal commitment must be based on a judicial order, urgent hospitalization has traditionally been within the exclusive control of psychiatrists, and until 1988, was regulated only by unpublished administrative guidelines.

In retrospect, repressive use of psychiatric power in the former Soviet Union seems to have been nearly inevitable. The practice of involuntary psychiatric treatment presents an unavoidable risk of mistake and abuse, even in a liberal, pluralistic society. This intrinsic risk was greatly magnified in the Soviet Union by the communist regime's intolerance for dissent, including any form of political or religious deviance, and by the corrosive effects of corruption and intimidation in all spheres of social life. Psychiatrists were not immune from these pressures. It therefore seems likely that a small subset of Soviet psychiatrists, associated primarily with Moscow's Serbski Institute for General and Forensic Psychiatry, knowingly collaborated with the KGB to subject mentally healthy dissidents to psychiatric punishment, in blatant violation of professional ethics and human rights. In this respect, abuse of psychiatry in the Soviet Union had less to do with psychiatry per se than with the repressiveness of the political regime of which the psychiatrists were a part. Fortunately, democratization seems to have brought the most blatant abuses to an end, and reformers are wisely attempting to establish counterforces to prevent renewed collaboration in the event that a repressive regime is reinstated.

In my view, however, corruption does not fully explain Soviet psychiatric abuse. The pattern of abuse that has been revealed was too pervasive to be attributable to a few corrupt doctors. The U.S. delegation declined to speculate about the motivations of the examining psychiatrists: "It is not possible in this type of study to determine whether [the Soviet psychiatrists'] diagnoses were based on idiosyncratic medical considerations alone or if political pressures influenced their judgment, thus resulting in deliberate misuse of psychiatry for purposes of social control." I believe that both of these explanations account for the observed pattern of abuse. In some cases, abuse was undoubtedly attributable to intentional misdiagnosis and to knowing complicity by individual psychiatrists in an officially directed effort to repress dissident behavior. In other cases, the elastic conception of mental disorder used in Soviet psychiatry was probably bent to political purposes, with individual psychiatrists closing their eyes to whatever doubts they may have had about the consequences of their actions. (Depending on the psychiatrists' degree of doubt, of course, the one explanation blurs into the other.)

The roots of the problem lie much deeper in the attitudes and training of Soviet psychiatrists and in the role of psychiatry in Soviet society. Repression of political and religious dissidents was only the most overt symptom of an authoritarian system of psychiatric care in which an expansive and elastic view of mental disorder encompassed all forms of unortho- 
dox thinking and in which psychiatric diagnosis was essentially an exercise of social power. ${ }^{3}$

At one time or another, 24 of the 27 patients interviewed by the U.S. delegation had received a diagnosis of schizophrenia. Under the prevailing diagnostic system in the Soviet Union, usually identified with Sneyzhneyvsky, the concept of schizophrenia includes mild ("sluggish") and moderate forms which are characterized not by active psychotic symptoms but rather by alterations of personality. As the delegation pointed out in its report:

Some of the symptoms incorporated into Soviet diagnostic criteria for mild ("sluggish") schizophrenia and, in part, for moderate (paranoid) schizophrenia are not accepted as evidence of psychopathology in the U.S. or under international diagnostic criteria. Specific idiosyncratic examples identified in the interviews included diagnosing individuals demonstrating for political causes as having a "delusion of reformism" or "heightened sense of self-esteem" to support a diagnosis of schizophrenia (Ref. 1, p 3).

In the mid-1980s, Soviet psychiatric officials began to acknowledge that a pattern of "hyperdiagnosis" had resulted in inappropriate psychiatric labeling and unnecessary hospitalization in the Soviet Union. ${ }^{10}$ It was therefore noteworthy that Soviet psychiatrists who interviewed the 27 patients concurrently with the U.S. team in 1989 found no current evidence of schizophrenia in the cases of 14 patients who were thought to be without mental disorder by the U.S. psychiatrists. However, it is also noteworthy that the Soviet psychiatrists nonetheless retained some psychiatric diagnosis for most of these patients. In this respect, the U.S. delegation found continuing evidence of hyperdiagnosis, particularly in the tendency to characterize these patients as having "psychopathy," a term that seems to be roughly equivalent to the general concept of personality disorder. Specific examples of "psychopathic" symptoms identified in the interviews by Soviet psychiatrists included "unitary activity," which related to a high level of commitment to a single cause, such as political reform, and "failure to adapt to society," which was used to describe a dissident patient who was "unable to live in society without being subject to arrest for his behavior."

One of the Soviet psychiatrists was asked whether a patient who had been sent to a special hospital for distributing anti-Soviet leaflets presented a danger to society. "Of course not," he responded. "Everything the patient distributed can be read in the newspapers now." 1 As this observation implies, what had changed was the meaning of a socially dangerous act, not the meaning of mental disorder. The end of political hospitalization in the Soviet Union was attributable to changes in Soviet politics, not to changes in Soviet psychiatry. In regard to psychiatry, the symptoms have receded, but the underlying condition remains untreated, even today. ${ }^{3}$

\section{Impact in the United States}

My colleague Lynda Frost and I recently published a book on the development of mental health law over the last three decades of the 20th century. ${ }^{11}$ One of the chapters we commissioned for the book was an essay on the reform of mental health law in Russia and other post-Soviet states in the wake of the political abuse of psychiatry in that country. ${ }^{12}$ During the peer-review process, some reviewers observed that the chapter seemed out of place in a book about the evolution of mental health law in the United States. I persuaded our editor to the contrary, that the chapter belonged in the book for two reasons, both of which are pertinent here: First, Soviet political abuse influenced mental health law in the United States at a formative stage of its development. Second, mental health law in this country has had a profound impact on the development of mental health legislation in other countries, including Russia, and on the shape of international human rights norms pertaining to psychiatric care.

One of the important purposes of mental health law reform in the 1960s and 1970s was to bring coercive psychiatry within reach of the rule of law. Even though libertarian and therapeutic approaches to involuntary treatment continue to vie for dominance, everyone recognizes that psychiatric discretion to hospitalize and treat a person over his or her objection should be constrained by socially prescribed criteria and disciplined by independent external review. This is because coercive intervention, however well-intentioned, carries with it an inevitable risk of mistake and abuse. (By "mistake," I mean outright clinical errors or unduly broad applications of clinical or legal criteria; by "abuse," I mean intentional misdiagnosis or misapplication of the governing criteria - a possibility that arises in even the most progressive society because, after all, human beings are corruptible everywhere.) These concerns are greatest when the criteria for involuntary treatment are most vague and when clinical diagnoses are most elastic and uncertain. 
The risks of mistake and abuse are accentuated in authoritarian cultures (even if they are not politically repressive) because pluralism and tolerance of individual differences tend to push psychiatric (and judicial) judgments in the direction of individual freedom in ambiguous cases, whereas authoritarian tendencies push in the opposite direction. In addition, psychiatrists in authoritarian cultures are more likely to see people as "diagnoses," rather than as individuals, leading to less flexibility in clinical decision-making than in more pluralistic societies. These patterns remain evident in posttotalitarian Russia. ${ }^{3}$

The risks of mistake and abuse are further magnified, of course, in totalitarian societies, where the state has the power and inclination to bend all institutions to its will, and where the counterforces may be weak or nonexistent, depending on the country's pretotalitarian history. In the Soviet Union for example, the inherent tendencies toward mistake (broad application of elastic diagnoses such as "sluggish" [latent] schizophrenia) and abuse (outright misdiagnosis) were not checked by either the professional culture or the legal system. No independent professional institutions and no legal culture had developed before the 1917 revolution. As a result, the psychiatric profession (if that is the right word in such a context) had no control over its own training and no ethical autonomy. In fact, the training of psychiatrists was brief, superficial, and dehumanized, leading to a well-documented pattern of hyperdiagnosis in all contexts, forensic and nonforensic, "political" and nonpolitical. As I suggested earlier, political abuse of psychiatry in the Soviet Union was inevitable; the only question is why it was not more widespread than it appears to have been.

What was the impact of the controversy surrounding Soviet political abuse of psychiatry on the evolution of mental health law in the United States? The Soviet experience was significant because it provided a vivid illustration of the risks associated with unchecked psychiatric power, and the importance of erecting institutional safeguards to minimize these risks in the context of involuntary hospitalization and treatment. It also helped to shape the understanding of ethics of the founding leaders of forensic psychiatry as a specialized discipline in the United States. American forensic psychiatry developed its professional identity and ethical autonomy at the same time the controversy about Soviet psychiatry was unfolding. (The American Academy of Psychiatry and the Law was established in 1971.)

Finally, the Soviet experience has helped to flesh out basic principles of medical ethics in the United States and world wide. Consider the core principle that psychiatrists should maintain their clinical independence and should not bend their opinions to the will of the state or another third party. ${ }^{13-15}$ What are the implications of this principle for managed care utilization review and for a variety of nontherapeutic social roles that psychiatrists sometimes serve (e.g., the assessment of execution competence $\left.{ }^{16}\right)$ ? When are apparently therapeutic interventions illegitimate? Consider coerced treatment of sexually violent offenders ${ }^{17}$ or of condemned prisoners on death row when the effect of treatment is to enable an execution to go forward. ${ }^{18}$ Injunctions against basing diagnoses on political values or religious beliefs and against using psychiatric interventions for "nonmedical" purposes have also been codified in various statements of ethics issued by international organizations, including the $\mathrm{WPA}^{14}$ and the World Medical Association. ${ }^{19}$ All these threads, as well as the principles of external review of psychiatric judgments, are woven together in the Principles for the Protection of Persons with Mental Illness and for the Improvement of Mental Health Care, approved by the United Nations General Assembly in $1991 .^{20}$ As Munro points out, what eventually became the U.N. Principles began with a 1986 report focusing heavily on the problem of political abuse, and highlighting the need for legal control over coercive psychiatry. ${ }^{4}$

The story of Soviet psychiatry came full circle in 1992 when the liberty-protecting norms of U.S. mental health law and the core principles of ethics regarding professional independence were codified in Russia's new mental health law. ${ }^{12,21}$ Similar laws have also been enacted in other former Soviet republics since $1992 .{ }^{3}$ In sum, the abuses of Soviet psychiatry and the deeper problems raised by unregulated use of coercion in psychiatric care have been inseparably linked with contemporary developments in mental health law and psychiatric ethics in the United States and in the international arena.

\section{Chinese Psychiatry}

Before publication of Robin Munro's recent articles, information on political abuse of psychiatry in China was limited to the occasional case report, together with a large reservoir of suspicion. The pool of 
available information was very shallow, especially in comparison with the steady stream of reports from the Soviet Union in the 1970s and 1980s. Munro's most important contribution is his painstaking and thorough review of the Chinese psychiatric literature and the official data on forensic assessments, which he has integrated with case reports and placed in the context of China's tumultuous political history over the past 50 years. His lengthy article in the Columbia Journal of Asian Law, published in the spring of $2001,{ }^{4}$ is an informative and persuasive account of the role of psychiatry in the regime's repression of dissent.

In light of the criticisms that have been lodged against Munro's account, I want to emphasize several points. First, Munro hews very closely to the historical record and the published data. Whenever he suggests that the data point in the direction of political abuse, he carefully acknowledges the possibility of alternative interpretations. His balanced presentation and interpretation strengthen my own confidence in the accuracy of his research and in the power of the inferences he draws. Second, the major portion of Munro's research traces the role of psychiatry in China's political history from the 1949 revolution through the Cultural Revolution and during the two decades after the Cultural Revolution into the late 1990s. The basic story line about political abuse follows this path. Only the last few pages of the article refer to the regime's repression of the Falun Gong, a practice that emerged during the latter half of 1999.

Munro's account of the Falun Gong story in the Columbia Journal of Asian Law is limited to case reports, and is presented tentatively. As he also points out, the regime's all-out efforts to disrupt the Falun Gong, including apparently pervasive use of psychiatric intervention, reflects a significant departure from the patterns that had been emerging in political cases over the previous decade. In short, Munro's well-formed views about the ebb and flow of political abuse since the Communist takeover is accompanied by tentative and sketchy accounts of the newly breaking Falun Gong experience. For this reason, the unsettled debate about the mental status of Falun Gong practitioners who have been hospitalized in recent months should not be allowed to obscure Munro's well-documented and important historical contribution on the history of political abuse in China during the past 50 years, especially its connections to the Soviet experience.
Munro's research indicates, convincingly in my view, that the Soviet system of forensic psychiatry was transplanted to China during the 1950s and 1960s, thereby placing a small subset of psychiatrists at the intersection of criminal prosecution and psychiatric confinement, and importing a smoothly oiled process by which psychiatrists found that most offenders referred for assessment lacked criminal responsibility and committed them for treatment without any adjudication or judicial oversight. Eventually, in the 1980s, China also established a system of maximum-security forensic hospitals (Ankang), modeled after the Soviet "special hospitals," for confining offenders who present a "social danger." Munro also shows that a substantial proportion of cases referred for forensic assessment involved "political" offenses, and that most of these offenders were diagnosed as schizophrenic, found nonresponsible, and committed to the Ankang facilities. The proportions of "political" cases have varied over the years, in apparent response to changing ideologic characteristics of the regime, but the basic Soviet-inspired structure has remained intact.

Among Munro's most interesting findings is the high proportion of political cases among those referred for forensic evaluation during the tumultuous period in 20th century Chinese political history known as the Cultural Revolution (1966-1976). For example, a survey of forensic assessments at a Shanghai hospital in 1970 to 1971 reported that 73 percent of the cases were political. Even among mentally retarded people referred for forensic assessment in 1960 to 1976 , almost a third were being prosecuted for political offenses. A 1987 study of forensic assessments performed at a Hangzhou hospital reported that the proportion of examinees arrested for "antisocial political speech" reached 54 percent in 1977, falling to 6.7 percent in 1987. Surely, there can be little doubt that the prevailing political ideology was shaping forensic practice, as it shaped everything else, during the Cultural Revolution.

Munro's analysis leaves little doubt that the prevailing ideology also shaped forensic practice before and after the Cultural Revolution. He quotes passages from two forensic texts in 1983 and 1994 in which a distinction is drawn between genuine counterrevolutionaries and "political lunatics" (a distinction that became "grotesquely blurred," as Munro puts it, during the Cultural Revolution). Obviously, some people who have mental disorders manifest 
their illness through "political" (or religious) conduct, and their beliefs may be delusional. The underlying questions, of course, are whether "political lunatics" are "really" mentally ill, and if not, whether the explanation for their diagnoses is corruption or culture.

I am persuaded by Munro's account that many of these offenders are not mentally ill according to generally accepted international diagnostic standards. It seems highly unlikely that mental illness is so prevalent among political offenders, or that the proportion of political offenders found among forensic examinees reflects their proportion in the arrestee population. The proportion of political offenders referred for examination and found nonresponsible is naturally higher than in the in the United States (because the conduct is not criminally prosecutable here) but it is also considerably higher than appears to have been the case in the Soviet Union. The point is made even more compelling by the increases and decreases in forensic referrals in response to changes in the policy of the regime. Putting the Cultural Revolution to one side, Munro shows that the proportion of political cases seems to have dropped from 10 to 15 percent during the Deng era to only a few percent during the latter part of the 1990s.

As for whether the forensic examiners are colluding with the state, Munro also opts for the more complicated explanation of the observed pattern of abuse. In addition to the examiners' fear of crossing the authorities, Munro refers to "the professional acculturation process, in which psychiatrists learn from the official medical literature. . that certain types of ideologically nonconformist behavior are attributable to severe and dangerous forms of 'mental pathology' " (Ref. 4, p 121). In addition, he takes note of the strong emphasis in Chinese-style Marxism on "correct thinking" and suggests that deviation from the prescribed line is even more puzzling to authorities and to psychiatrists than it was in the Soviet Union. The dissidents in China are more likely to be viewed as mentally abnormal because they appear to lack "any normal instinct for self-preservation."

To the extent that psychiatric abuse is a chosen form of repression, rather than a reflection of culturally grounded diagnoses of "political lunacy," we must also ask why the regime sometimes chooses psychiatric punishment in lieu of the labor camp and why the use of psychiatric punishment waxes and wanes. This question has always puzzled me about the Soviet experience. Why, when so many dissidents were sent to labor camps, were some chosen for psychiatric repression? In a previous issue of this journal, ${ }^{22}$ Ukrainian psychiatrist Semyon Gluzman, who spent seven years in a labor camp for exposing Soviet abuse of psychiatry, offers this answer:

Complete totalitarianism does not resort to psychiatric camouflage. Such was the nature of totalitarianism during the time of Stalin. However, Brezhnev's totalitarianism (which I would define as "exhausted or tired" totalitarianism) did not enjoy that absolute power, and for this reason, psychiatric repression was used as a frightening "super weapon" which was far more horrible than the usual prisons and camps (Ref. 22, p 332).

In China, the Cultural Revolution brought on a period of "frenzied totalitarianism," including what the Deng regime readily conceded to be "excesses" of all kinds. Munro suggests, in a variation on Gluzman's hypothesis, that the new reformist orientation of the Deng regime would not allow them to "liquidate" their opposition and that they needed a "more elaborate mechanism of inducing long-term fear" among their ideological enemies.

\section{Prospects for Change}

Political abuse of psychiatry ended in Russia and the other former Soviet states, not because psychiatry changed, but because the politics did. The totalitarian regime "tired," changed direction (under Gorbachev), and finally collapsed. Notwithstanding the 1992 mental health legislation, coercive psychiatry remains largely unregulated and shaped by the same tendencies toward hyperdiagnosis and overreliance on institutional care that characterized the communist era. There are hopeful signs of professional independence and consumer advocacy, but little has actually changed in the culture or in professional practice. The challenge of mental health reform in Russia and the other former Soviet states is a daunting one. ${ }^{3}$

There is no sign that the Chinese regime is tiring, or that economic reform will be accompanied by democratization in political life, or that its change in direction will lead to collapse. As long as counterrevolutionary behavior is punished, some portion of these cases will be processed through the Ankang system. As long as the regime feels so strongly threatened by Falun Gong, it will lash out against its adherents. Local authorities, employers, and worried families will expect psychiatrists to respond clinically to what is, after all, indisputably deviant behavior. In 
this context, what is the most promising path of change?

The only plausible course, it seems to me, is to separate the two threads of the problem: human rights and medical ethics. We should assume that respect for human rights in China is not a foreseeable outcome in the short term. In the Soviet case, the Helsinki process gave the United States a powerful source of leverage for insisting on proof that repressive practices had ended and that all political prisoners and prisoners of conscience had been released from prisons and psychiatric hospitals. The 1989 visit of the U.S. State Department delegation "to assess recent changes in Soviet psychiatry" was a direct outgrowth of the Helsinki process, as was the Soviet Union's desire to win readmission to the WPA. In the case of China, the international community does not appear to be willing to press the regime on human rights, and therefore the path toward ending political abuse will not be through political liberalization. Instead, the only available path, in the short term, is through Chinese psychiatry, using the collegial pressure of international psychiatric and medical organizations.

It is conceivable that the Chinese regime would find it useful to dispel the cloud of professional embarrassment in the world psychiatric community. It could do this by sending the message to police and prosecutorial agencies that political cases should no longer be put on a forensic path. This would not end violations of human rights, but it would end the practice of psychiatric punishment. The regime could also send the message that psychiatrists in ordinary hospitals are not expected to hospitalize Falun Gong practitioners or others who have defied the regime, and that such people, though misguided and foolhardy, are not necessarily mentally ill. Of course, I am assuming that the state has other methods of repression at its disposal and that it could give up the psychiatric threat without abandoning its effort to suppress the movement. Again, this approach would not end violations of human rights, but it would end the practice of psychiatric punishment.

Would this be a victory? Obviously, it would not be a substantial victory for human rights in China. However, it would be a victory for Chinese psychiatrists, whose exposure to intimidation would be reduced. It would be a victory for world psychiatry, whose professional solidarity would be invoked and reaffirmed in support of the profession's highest eth- ical ideals. It would also be a modest victory for political and religious dissidents whose willingness to stand up for their beliefs would no longer be devalued by attributions of mental illness. (Of course, some of the people for whom hospitalization is sought are mentally ill, and psychiatrists should not shrink from the ethical duty to treat those in need.) The point is that psychiatrists would be emboldened to act independently. That would be a big step in the direction of establishing embryonic safeguards against future abuse. So, too, would be the enactment of the new mental health legislation that has been undergoing review and revision since 1985 and the new regulation for forensic psychiatry, which would expose this heretofore invisible process to judicial scrutiny.

\section{Human Rights and Medical Ethics}

As I mentioned earlier, concerns about political abuse have played a significant role in the evolution of international norms of mental health and codes of psychiatric ethics. However, this link has not been uniformly welcomed. For one thing, if the risk of political abuse is exaggerated, it can become a rhetorical bumper sticker for strictly libertarian criteria for involuntary treatment and even for abolition of coerced treatment. The beneficent aspirations of psychiatry (and the fidelity of most psychiatrists to patient-centered norms) can easily be obscured by a cloud of distrust.

Adherents of a more therapeutic approach to mental health law and of a more paternalistic view of psychiatric ethics believe that the world psychiatric community has unthinkingly abandoned its traditional principles of ethics in favor of the libertarian approach that has so dominated mental health law in the United States. For example, international codes of psychiatric ethics proclaim that dangerousness should be a necessary predicate for coercive treatment ${ }^{15}$ and that hospitalization should be permitted only if there is no less-restrictive alternative ${ }^{13}$ — principles that preclude coerced hospitalization in cases in which it may be therapeutically indicated. Defenders of traditional therapeutic ethics are also justly suspicious of allegations of political abuse, especially when the "accused" psychiatrists claim that the patients in question are actually mentally ill and in need of treatment to alleviate suffering and reverse serious deterioration. 
It seems that the current debate about Chinese psychiatry, especially the controversy surrounding the Falun Gong, has exposed the fault lines of modern mental health law and stirred up the dying embers of the antipsychiatry movement. Although many psychiatrists stand in the front lines of the effort to censor "official" Chinese psychiatry, others stand in solidarity with Chinese psychiatrists to defend them against what they perceive as the antipsychiatry biases of human rights lawyers.

I happen to agree with the view that the world psychiatric community has allowed its major ethics statements to be highjacked by libertarian values. I also believe that most Chinese psychiatrists do not participate in the repressive practices described by Munro and that many of those who do participate have themselves been victimized by intimidation. But these are not reasons to circle the wagons around Chinese psychiatry. The world psychiatric community has not been forceful enough in responding to the reports of political abuse in China. The evidence so carefully assembled by Robin Munro must be taken seriously and should galvanize the world psychiatric community into action - to stand up for the ethical integrity of Chinese psychiatrists and to press the Chinese government to do the same.

\section{References}

1. Report of the U.S. Delegation to assess recent changes in Soviet psychiatry, July 12, 1989, together with the Soviet response. Schizophrenia Bull 15(suppl):1-216, 1989

2. Smith T: No Asylum: State Psychiatric Repression in the Former USSR. New York: New York University Press, 1996

3. Bonnie R, Polubinskaya S: Unraveling Soviet psychiatry. J Contemp Leg Issues 10:279-98, 1999

4. Munro R: Judicial psychiatry in China and its political abuses. Columbia Journal of Asian Law 14:1-128, 2000

5. Bloch S, Reddaway P: Soviet Psychiatric Abuse: Shadow Over World Psychiatry. London: Victor Gollancz, 1984
6. Koryagin A: Unwilling patients. Lancet 1(8224):821-4, 1981

7. Baker J: Nonimputability in Soviet criminal law: The Soviet approach to the insanity plea. Law Psychol Rev 11:55-102, 1987

8. Bonnie R: Coercive psychiatry and human rights: an assessment of recent changes in the Soviet Union. Criminal Law Forum 1:31946, 1990

9. Sneyzhneyvsky AV: The symptomatology, clinical forms and nosology of schizophrenia, in Modern Perspectives in World Psychiatry. Edited by Howells JG. New York: Brunner/Mazel, 1971, pp 425-47

10. Churkin A: Psychiatry and politics: interview with Chief Psychiatrist of the U.S.S.R. Ministry of Health. New Times 43:41-3, 1988

11. Frost L, Bonnie R: The Evolution of Mental Health Law. Washington, DC: American Psychological Association, 2001

12. Polubinskaya S: Law and psychiatry in Russia: looking backward and forward, in The Evolution of Mental Health Law. Edited by Frost L, Bonnie R. Washington, DC: American Psychological Association 2001, pp 113-25

13. Statement and Viewpoints on the Rights and Legal Safeguards of the Mentally Ill, as approved by the General Assembly of the World Psychiatric Association in Athens, Greece, October 17, 1989

14. Declaration of Hawaii, as approved by the General Assembly of the World Psychiatric Association in Vienna, Austria, July 10, 1983

15. Declaration of Madrid, as approved by the General Assembly of the World Psychiatric Association in Madrid, Spain, August 25, 1996

16. Bloche MG: Clinical loyalties and the social purposes of medicine. JAMA 281:268-74, 1999

17. Task Force Report on Dangerous Sex Offenders. Washington, DC: American Psychiatric Association, 1999

18. Bonnie R: The death penalty: when doctors must say no. BMJ 305:381-2, 1992

19. World Medical Association: Declaration of Tokyo, 1975, reprinted in The Medical Profession and Human Rights. London: British Medical Association, 2001, pp 539-40

20. Principles for the Protection of Persons with Mental Illness and the Improvement of Mental Health Care, 1991. G. A. Res. 199, U.N. GAOR, 46th Sess., Supp. No. 49, Annex, pp. 188-192, 1991. U.N. Doc.A/46/49

21. Bonnie R. Introduction: the evolution of the 1992 law of the Russian Federation on Psychiatric Care. J Russian Eur Psychiatry 27:69-96, 1996

22. Gluzman S: Law and psychiatry: the totalitarian experience. J Am Acad Psychiatry Law 29:330-5, 2001 